\title{
Efficacy of Levofloxacin, Chitosan and EDTA Combination against Methicillin Resistant Staphylococcus Aureus Skin Infections: In Vitro and In Vivo Evaluations
}

Aliasgar F. Shahiwala*, Gazala A. Khan, Nadiya M. Bostanooei

Dubai Pharmacy College, Muhaisnah 1, Dubai, United Arab Emirates

\begin{abstract}
Antibiotic resistance is one of the greatest threats to modern health and most of the bacteria are resistant to one or more antibiotics. Methicillin Resistant Staphylococcus Aureus (MRSA)bacteria are almost always found to be resistant to multiple antibiotics. In this research, effort has been made to see the efficacy of Levofloxacin (LF) in combination of chitosan $(\mathrm{CH})$ and ethylene diaminetetraacetic acid (EDTA) in overcoming antibiotic resistance in MRSA strain. MIC and MBC were determined by standard broth dilution method for $\mathrm{LF}$ alone and $\mathrm{LF}+\mathrm{CH}, \mathrm{CH}+\mathrm{EDTA}$ and $\mathrm{LF}+\mathrm{CH}+\mathrm{EDTA}$ combinations. The rate of killing of SA and MRSA by the $\mathrm{LF}+\mathrm{CH}+\mathrm{EDTA}$ were carried out at $2 \mathrm{xMIC}$ and $4 \mathrm{xMIC}$ concentrations. The efficacy of $\mathrm{LF}+\mathrm{CH}+\mathrm{EDTA}$ was also evaluated in vivo on MRSA infected skin wounds in rat model compared to LF alone.

Results of antimicrobial studies showedfour fold reduction in minimum inhibitory concentration (MIC) and minimum bactericidal concentration $(\mathrm{MBC})$ by $\mathrm{LF}+\mathrm{CH}+\mathrm{EDTA}$ compared to $\mathrm{LF}$ alone.Complete eradication of MRSA was observed when treated with $\mathrm{LF}+\mathrm{CH}+\mathrm{EDTA}$ at $2 \mathrm{xMIC}$ concentration within $6 \mathrm{hrs}$. The results of antimicrobial studies were further confirmed by animal studies. LF+CH+EDTA treated group showed significant reduction in the diameter of infected area on animal skin from Day 1 of the treatment $(\mathrm{p}<0.05)$ compared to both control and plain drug treated group and complete absence of the infected area was observed after 4 th day of treatment.Thus, it is concluded that LF+CH+EDTA combination is a potential system in overcoming antibiotic resistance. However, further studies with other antibiotic resistant bacterial strains need to be conducted to generalize the applicability of this investigation.
\end{abstract}

\section{Introduction}

The treatment of bacterial infections is increasingly complicated by the ability of bacteria to develop resistance to antimicrobial agents often results in treatment failure. WHO has identified that urgent and coordinated action is required at local, national, and international levels to ensure the adequate treatment of patients today and the preservation of the life-saving power of antimicrobials for future generations. With increase in antimicrobial use and misuse, the level and complexity of the resistance mechanisms exhibited by bacterial pathogens have also increase dramatically. Several mechanisms have evolved in bacteria which confer them with antibiotic resistance. These mechanisms can chemically modify the antibiotic, render it inactive through physical removal from the cell, or modify target site so that it is not recognized by the antibiotic [1-3].

Bacterial resistance to antibiotics has been a recognized reality almost since the dawn of the antibiotic era, but only within the past twenty years has the emergence of dangerous, resistant strains occurred with a disturbing regularity. This escalating evolution of resistance coupled with a diminished antibiotic pipeline has led some to claim that a post-antibiotic era is eminent [4]. The annual impact of resistant infections is estimated to be $\$ 20$ billion in excess health care costs and 8 million additional hospital days in the United States (US) $[5,6]$ and over $1.6 €$ billion and 2.5 million additional hospital days in the European Union (EU) [7].

S. aureus is a gram positive, facultative anaerobic pathogen with both hospital and community acquired strains. Though traditionally opportunistic, many S. aureus strains are now aggressively pathogenic [8]. It is the most common skin bacterium with $60 \%$ of humans being intermittent carriers and 20\% being persistent carriers, chronically harboring at least one strain [9].

MRSA is considered to be one of the 18 microbes listed by the CDC as a multidrug-resistant microbe or "superbug" [10]. MRSA is known for causing skin infections in addition to many other types of infections. The majority of MRSA infections are classified as CAMRSA (community acquired) or HA-MRSA (hospital- or health-careacquired) [11]. Statistical data suggest that as many as 19,000 people per year have died from MRSA in the U.S. Data supplied by the CDC in 2011 suggests this number has declined by about $54 \%$ from 2005 to 2011, in part, because of prevention practices at hospitals and home care. In addition, hospital deaths from MRSA infection have declined by about 9,000 per year from 2005-2011. However, the CDC recently estimated about 80,000 infections with 11,000 deaths occurred in 2011, but they suggest that a far greater number of minor infections occurred in both the community and in hospitals.

Currently, MRSA bacteria are almost always found to be resistant to multiple antibiotics [11]. All isolated MRSA strains need to have

"Corresponding Author: Prof. Aliasgar Shahiwala, Professor \& Graduate Program Director, Dubai Pharmacy College, Dubai, Tel.(M): +971552563898, Fax:+97142646740; E-mail: alishahiwala@gmail.com

Citation: ShahiwalaAF, Khan GA, Bostanooei NM (2017) Efficacy of Levofloxacin, Chitosan and EDTA Combination against Methicillin Resistant Staphylococcus Aureus Skin Infections: In Vitro and In Vivo Evaluations. Int J Clin Med Microbiol 2: 121. doi: https://doi.org/10.15344/2456-4028/2017/121

Copyright: (c) 2017 Shahiwala et al. This is an open-access article distributed under the terms of the Creative Commons Attribution License, which permits unrestricted use, distribution, and reproduction in any medium, provided the original author and source are credited. 
Citation: Shahiwala AF, Khan GA, Bostanooei NM (2017) Efficacy of Levofloxacin, Chitosan and EDTA Combination against Methicillin Resistant Staphylococcus Aureus Skin Infections: In Vitro and In Vivo Evaluations. Int J Clin Med Microbiol 2: 121. doi: https://doi.org/10.15344/2456-4028/2017/121

Page 2 of 6

antibiotic susceptibility determined to choose the correct or appropriate antibiotic therapy. Treatment of HA-MRSA frequently involves the use of vancomycin, often in combination with other antibiotics given by IV. CA-MRSA can often be treated on an outpatient basis with specific oral or topical antibiotics, but some serious CA-MRSA infections (for example, pneumonia) often require appropriate antibiotics by IV.

Chitosan, a positively charged polysaccharide biopolymer derived from chitin, exhibits a number of interesting biological properties such as wound healing ability, antimicrobial, and anti-inflammatory activities, and biodegradability [12-14]. Since it was first proposed for antimicrobial activity in 1979 [15], chitosan has drawn attention of many researchers.Chitosan has shown wide spectrum of antimicrobial activity against both gram positive and gram negative bacteria, fungi and yeasts [16-20].

Ethylenediaminetetraacetic acid (EDTA) is a widely known metalchelating agent, substantially used for the treatment of patients who've been poisoned with heavy metal ions together with mercury and lead. The impact of EDTA on bacteria appeared first in 1965 when Brown and Richards stated EDTA as a 'potentiator' of the activity of other antimicrobial agents [21]. EDTA has shown to potentiate the actions of other preservatives, antibiotics and cationic surfactants [22-25]. EDTA reversed the antibiotic resistance of tetracycline, penicillin or ampicillin when combined with these antibiotics in strains of Pseudomonas aeruginosa [26,27]. However, the mechanism of antibacterial effectiveness by EDTA is not fully known, it's chelating ability to bind with divalent cations, deprive the microorganisms of $\mathrm{Mg}^{2+}, \mathrm{Ca}^{2+}$, and $\mathrm{Fe}^{2+}$, which are essential factors for microbial growth EDTA was also shown to enhance destabilization of the $\mathrm{S}$ aureous [28]. The use of EDTA in combination with minocycline had shown increased bactericidal effect on antibiotic-resistant $S$. aureus cells [29].

The aim of this investigation was to evaluate the efficacy of levofloxacin in combinations with chitosan and chitosan-EDTA against both normal strain and resistant strain of SAin both in vitro and in vivo.

\section{Material and Methods}

Levofloxacin and EDTA were purchased from S. D. Fine Chemical Limited, Mumbai, India. Chitosan (degree of deacetylation $\geq 90 \%$ ) and bacterial media were purchased from HiMedia Laboratories Private Limited, Nasik, India. Methicillin Resistant Staphylococcus aureus (RHCC 3163) and Staphylococcus aureus (RHCC 2011) strains of bacteria were obtained from Rashid Hospital Microbial Culture Collection (RHCC), Rashid Hospital, Dubai, United Arab Emirates. Methicillin Resistant Staphylococcus aureus and Staphylococcus aureus were sub cultured from their respective stock culture and was sustained on Nutrient agar and Mannitol salt agar (MSA).

\section{Antibacterial studies}

Gram positive Methicillin Resistant Staphylococcus aureus bacteria (RHCC 3163) and Staphylococcus aureus strains of bacteria(RHCC 2011) were obtained from Rashid Hospital Microbial Culture Collection (RHCC), Rashid Hospital, Dubai, United Arab Emirates. Methicillin Resistant Staphylococcus aureus and Staphylococcus aureus were sub cultured from their respective stock culture and was sustained on Nutrient agar and Mannitol salt agar (MSA).

\section{Preparation of Drug Solution \& Formulation for Antibacterial studies}

For antibacterial studies, levofloxacin plain drug solution and combinations with chitosan and chitosan with EDTA were prepared in final concentrations of $1024 \mu \mathrm{g} / \mu \mathrm{l}, 512 \mu \mathrm{g} / \mu \mathrm{l}, 256 \mu \mathrm{g} / \mu \mathrm{l}, 128 \mu \mathrm{g} /$ $\mu \mathrm{l}, 64 \mu \mathrm{g} / \mu \mathrm{l}, 32 \mu \mathrm{g} / \mu \mathrm{l}, 16 \mu \mathrm{g} / \mu \mathrm{l}, 8 \mu \mathrm{g} / \mu \mathrm{l}$, and $4 \mu \mathrm{g} / \mu \mathrm{l}$ after sufficient dilutions.Nutrient Agar media was also prepared, autoclaved and cooled at $50^{\circ} \mathrm{C}$ and appropriate amount was plated in sterile petri plates under sterile conditions. The plates were allowed to cool and were refrigerated and used the next day.

\section{Determination of MIC by broth dilution method}

MIC (minimum inhibitory concentration) and MBC (minimum bactericidal concentration) were determined by broth dilution method as reported earlier [30].Inoculum was acquired from an overnight nutrient agar culture of the experimental organism. Inoculum for the MIC test was prepared by taking at least three to five well-isolated colonies of the same morphology from an agar plate culture. The top of each colony was touched with a sterile loop and the growth was transferred into a tube containing $15 \mathrm{ml}$ nutrient broth and incubated at $370 \mathrm{C}$ until it achieved the turbidity of the $0.5 \mathrm{McFarland}$ standards correspond to bacterial population of approximately $2 \times 108 \mathrm{cfu} / \mathrm{ml}$. From this, $0.5 \mathrm{ml}$ of bacterial culture and $4.5 \mathrm{ml}$ Mueller Hinton Broth was added to different concentrations of drug and incubated for 24 hours at 370Cto determine MIC and MBC.

\section{Time kill analysis}

Experiment for the rate of killing of the bacteria (SA and MRSA) by the $\mathrm{LF}+\mathrm{CH}+\mathrm{EDTA}$ were carried out using a modified time kill analysis technique of Eliopoulos and Eliopoulos and Eliopoulos and Moellering [31,32]. The nanoparticle was combined into $5 \mathrm{~mL}$ Mueller Hinton broth in sterile test tubes at $2 \times \mathrm{MIC}$ and $4 \times \mathrm{MIC}$. The test tubes were incubated at $37^{\circ} \mathrm{C}$. A $100 \mu \mathrm{L}$ sample was removed from the culture medium at various time intervals from $0-24$ hours for the determination of $\mathrm{cfu} / \mathrm{mL}$ by measuring optical density and by the plate count technique [33] by plating out $25 \mu \mathrm{L}$ of each of the dilutions on Nutrient agar.

After incubating at $37^{\circ} \mathrm{C}$ for $24 \mathrm{~h}$, growing bacterial colonies were counted, $\mathrm{cfu} / \mathrm{mL}$ calculated and compared with the count of the culture control without nanoparticle.

\section{Animal Studies}

Albino rats of either sex weighing between 200-250g from Lootah Technical centre, were used for the present investigation. Research and Animal Ethics Committee of Dubai Pharmacy College approved experimental protocol. The rats were housed at controlled temperature $\left(25 \pm 2^{\circ} \mathrm{C}\right)$ and $12 \mathrm{hrs}$ dark-light cycle and provided basal diet in the form of pellets, water ad libitum.

The rats were randomly divided into 3 groups of 3 animals each. First group was kept as control, without any treatment. The second group was treated with $0.1 \% \mathrm{w} / \mathrm{w} \mathrm{LF}$ formulated in $5 \%$ Hydroxypropyl methyl cellulose (HPMC) gel base. The third group was treated with $0.1 \% \mathrm{LF}+\mathrm{CH}+\mathrm{EDTA}$ in $5 \% \mathrm{HPMC}$ gel base.

MRSA skin infection animal model was used as reported earlier with slight modification [34]. The back of the rats were shaved and then mild burns were produced on their dorsal part under anesthesia 
Citation: Shahiwala AF, Khan GA, Bostanooei NM (2017) Efficacy of Levofloxacin, Chitosan and EDTA Combination against Methicillin Resistant Staphylococcus Aureus Skin Infections: In Vitro and In Vivo Evaluations. Int J Clin Med Microbiol 2: 121. doi: https://doi.org/10.15344/2456-4028/2017/121

Page 3 of 6

(diethyl ether) with the help of heated rod. After cleaning the underlying skin with normal saline, the bacterial suspension containing approximately $2 \times 108 \mathrm{cfu} / \mathrm{ml}$ of MRSA was applied on the burn skin with the help of sterile loop to produce MRSA skin infection and rats were kept 1 day without treated to observe visible growth of the bacteria. On the day 1, diameter of infected area was taken using vernier caliper and approximately, $0.5 \mathrm{gm}$ of LF gel and $\mathrm{LF}+\mathrm{CH}+\mathrm{EDTA}$ gel were applied to the respective groups. Control group was left untreated. The same procedure was repeated till Day 7.

\section{Histological Studies of infected skin}

The small portion of the skin were collected from the infected area of the animals on the last day of the experiment (Day 7) and preserved in $10 \%$ buffered formalin. Series of $3-4 \mu \mathrm{m}$ thickness sections were prepared and stained with hematoxylin-eosin and photographed under $100 \mathrm{x}$ or $450 \mathrm{x}$ magnification. The rate of re-epithelialization, skin structure and inflammatory cells were evaluated by a blind histopathologist.

\section{Results \& Discussion}

Minimum Inhibitory Concentration (MIC) and Minimum Bactericidal Concentration (MBC) were determined by means of standardized procedures. Levofloxacin in combination with chitosan and EDTA put forth an MIC of $16 \mu \mathrm{g} / \mathrm{ml}$ and MBC of $32 \mu \mathrm{g} / \mathrm{ml}$ on MRSA, whereas an MIC of $4 \mu \mathrm{g} / \mathrm{ml}$ and MBC of $8 \mu \mathrm{g} / \mathrm{ml}$ on SA (Table 1 ).
$\mathrm{LF}+\mathrm{CH}+\mathrm{EDTA}$ exerted bactericidal effect against SA even at much lower concentration $(8 \mu \mathrm{g} / \mathrm{ml})$ compared to resistant strain MRSA (32 $\mu \mathrm{g} / \mathrm{ml}$ ) (Table 1 ).

In comparison, $\mathrm{LF}+\mathrm{CH}$ exerted an MIC of $64 \mu \mathrm{g} / \mathrm{ml}$ and $\mathrm{MBC}$ of $128 \mu \mathrm{g} / \mathrm{ml}$ on $M R S A$, whereas an MIC of $32 \mu \mathrm{g} / \mathrm{ml}$ and $64 \mu \mathrm{g} / \mathrm{ml}$ on $S A$ and an MBC of $8 \mu \mathrm{g} / \mathrm{ml}$. Levofloxacin alone on the other hand exerted an MIC of $128 \mu \mathrm{g} / \mathrm{ml}$ and MBC of $256 \mu \mathrm{g} / \mathrm{ml}$ on $S A$, whereas an MIC of $256 \mu \mathrm{g} / \mathrm{ml}$ and $512 \mu \mathrm{g} / \mathrm{ml}$ on MRSA.

The time kill analysis is used to determine the bactericidal or bacteriostatic activity of antibacterials. Bactericidal effect of $\mathrm{LF}+\mathrm{CH}+\mathrm{EDTA}$ was assessed by time kill studies which showed that at its $2 \times$ MIC $(32 \mu \mathrm{g} / \mathrm{ml})$ and at $4 \times \mathrm{MIC}(128 \mu \mathrm{g} / \mathrm{ml})$ concentration for MRSA, the LF+CH+EDTA initiated significant decrease in the amount of bacteria (Figure 1). For both the concentrations complete killing of MRSA was observed after 6 hours of incubation. The killing effect was noticeable with MRSA where $>2 \log$ reduction were observed in $4 \mathrm{~h}$ post treatment.

Diameters of infected skin patches are recorded in Figure 2 and repeated measures ANOVA followed by post hoc analysis was performed on the data using SPSS software. Difference on each day of treatment between control and LF treated, control and LF+CH+EDTA treated and $\mathrm{LF}$ and $\mathrm{LF}+\mathrm{CH}+\mathrm{EDTA}$ treated groups were individually compared using post hoc analysis.

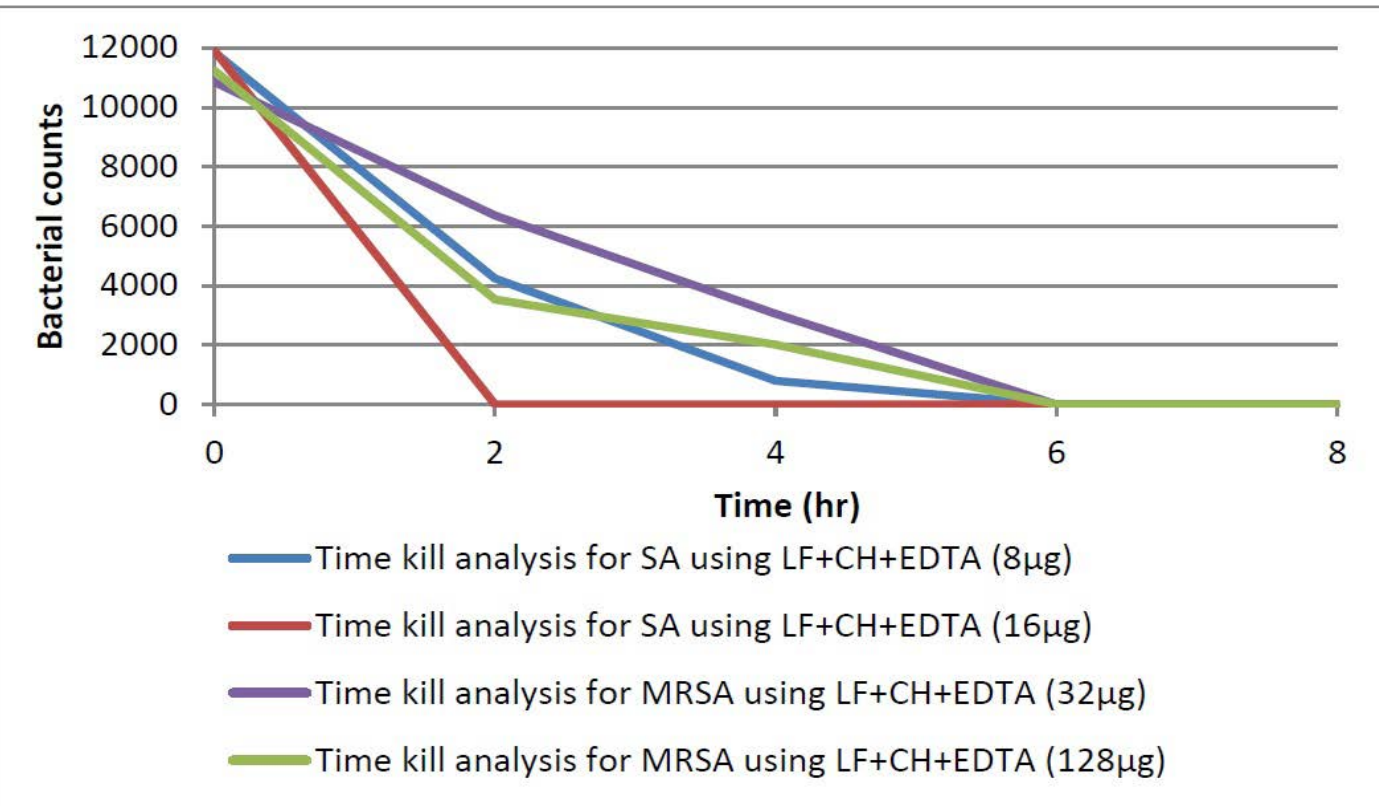

Figure 1: Time-kill Analysis of developed formula against SA and MRSA

\begin{tabular}{|c|c|c|c|c|}
\hline & Minimum Inhibitory Concentration $(\mu \mathrm{g})$ & & & \\
\hline & Staphylococcus Aureus & $\begin{array}{l}\text { Methicillin Resistant } \\
\text { Staphylococcus aureus }\end{array}$ & & \\
\hline & MIC & $\mathrm{MBC}$ & MIC & MBC \\
\hline $\mathrm{LF}(1 \mu \mathrm{g} / 1 \mu \mathrm{l})$ & 128 & 256 & 256 & 512 \\
\hline Chitosan $(1 \mu \mathrm{g} / 1 \mu \mathrm{l})$ & 1026 & $>1026$ & $>2052$ & $>2052$ \\
\hline $\mathrm{LF}+\mathrm{CH}(1 \mu \mathrm{g}$ each $/ 1 \mu \mathrm{l})$ & 32 & 126 & 124 & 512 \\
\hline $\mathrm{CH}+\operatorname{EDTA}(1 \mu \mathrm{g}$ each $/ 1 \mu \mathrm{l})$ & 512 & 1026 & 2052 & $>2052$ \\
\hline $\mathrm{LF}+\mathrm{CH}+\mathrm{EDTA}(1 \mu \mathrm{g}$ each $/ 1 \mu \mathrm{l})$ & 4 & 8 & 16 & 32 \\
\hline
\end{tabular}

Table 1: MIC and MBC of Levofloxacin Alone and in Combinations with Chitosan and EDTA. 
Citation: Shahiwala AF, Khan GA, Bostanooei NM (2017) Efficacy of Levofloxacin, Chitosan and EDTA Combination against Methicillin Resistant Staphylococcus Aureus Skin Infections: In Vitro and In Vivo Evaluations. Int J Clin Med Microbiol 2: 121. doi: https://doi.org/10.15344/2456-4028/2017/121

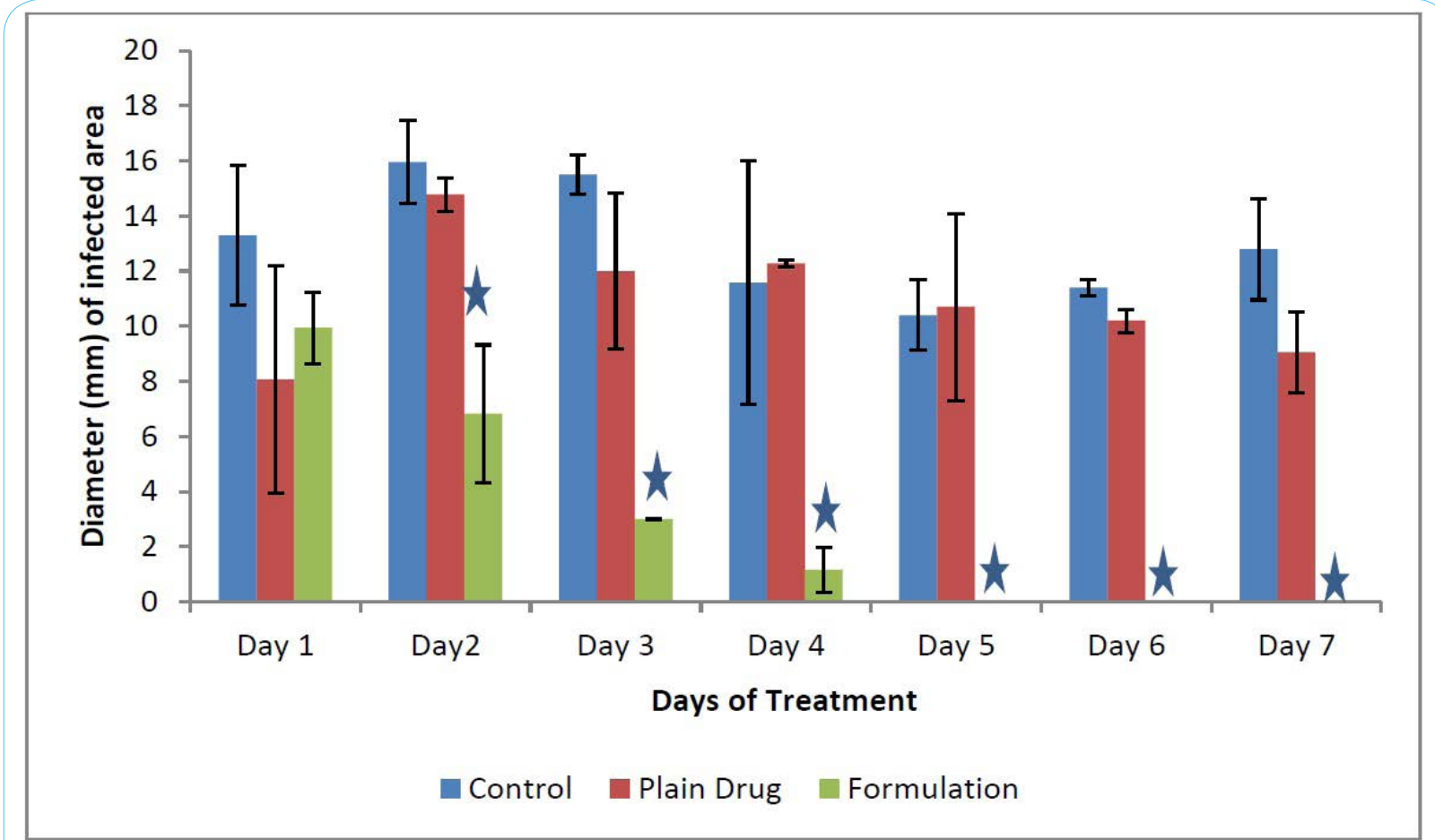

Figure 2: Diameters of infected wounds in different animal groups $(\mathrm{n}=3), \mathrm{p}<0.05$.
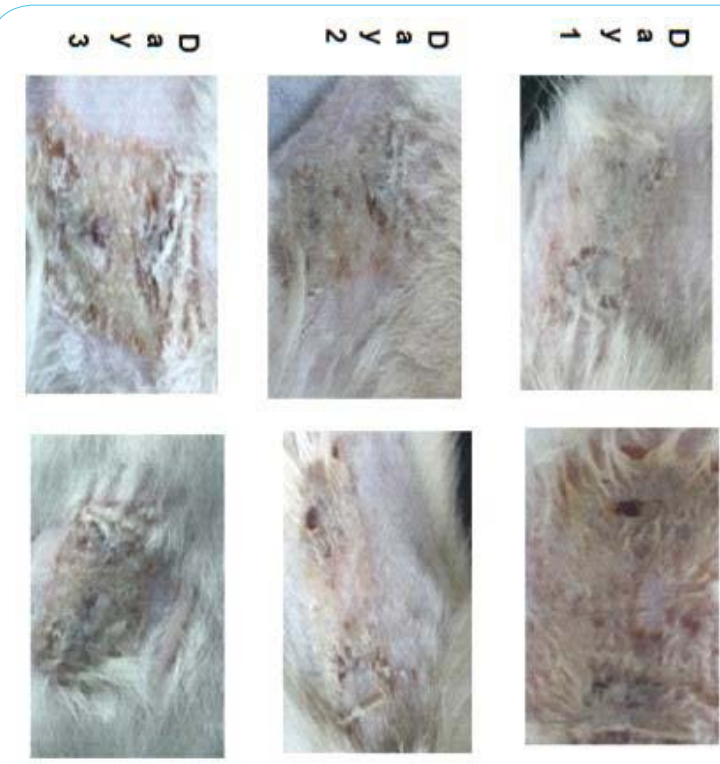

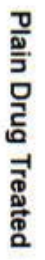
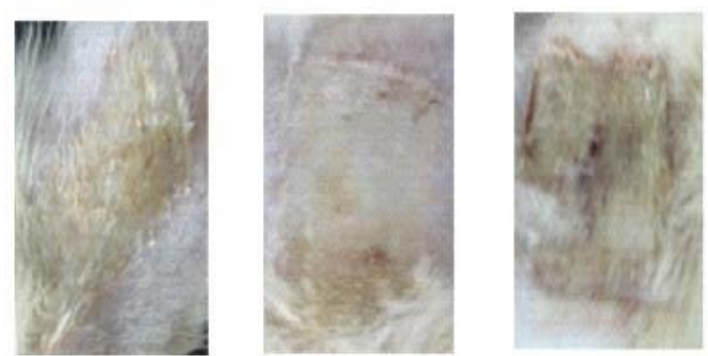

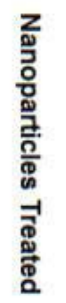

Figure 3: Images of infected skin area of rats.
Aliasgar F. Significant differences $(p<0.05)$ between the diameters of the infected patch amongst the animal groupswere found by ANOVA. Post hoc analysis suggest there is significant difference between control and LF+CH+EDTA treated group and plain drug and $\mathrm{LF}+\mathrm{CH}+\mathrm{EDTA}$ treated groups, however, there was no significant difference between control group and plain drug treated group. When results on individual days of treatment were compared using student's $t$ test, there is no significant difference $(p>0.05)$ between control and plain drug treated group on all the days of treatment. While, significant difference $(p<0.05)$ on all the days of treatment starting from the first day was observed between control and $\mathrm{LF}+\mathrm{CH}+\mathrm{EDTA}$ treated group and plain drug and $\mathrm{LF}+\mathrm{CH}+\mathrm{EDTA}$ treated groups. Plain drug formulation shown little effect only from the 5th day of treatment, however, the reduction was not significant $(\mathrm{p}>0.05)$. LF+CH+EDTA treated group showed significant reduction in the diameter of infected area on animal skin from Day 1 of the treatment $(\mathrm{p}<0.05)$ compared to both control and plain drug treated group and complete absence of the infected area was observed after 4th day of treatment.

The slides of skin sections were shown in Figure 3. The skin structure was found be normal in all the groups due to mild skin burn, epidermis layer was more or less intact. The presence of leukocytes in control group is indicating the infection in the dermis layer. However, in LF treated and LF+CH+EDTA treated groups, leukocytes were absent. Although, leukocytes were found absent in plain drug treated animals, visible observation of skin suggested the skin infection. However, in case of $\mathrm{LF}+\mathrm{CH}+\mathrm{EDTA}$ treated group both the visible observation and histopathological study (figure 4) suggest no infection proves complete eradication of bacterial infection.

\section{Discussion}

Antibiotic resistance is one of the greatest threats to modern health and most of the bacteria are developing increased resistance to antibiotics. The present study demonstrates the effectiveness of LF in 
Citation: Shahiwala AF, Khan GA, Bostanooei NM (2017) Efficacy of Levofloxacin, Chitosan and EDTA Combination against Methicillin Resistant Staphylococcus Aureus Skin Infections: In Vitro and In Vivo Evaluations. Int J Clin Med Microbiol 2: 121. doi: https://doi.org/10.15344/2456-4028/2017/121

Page 5 of 6
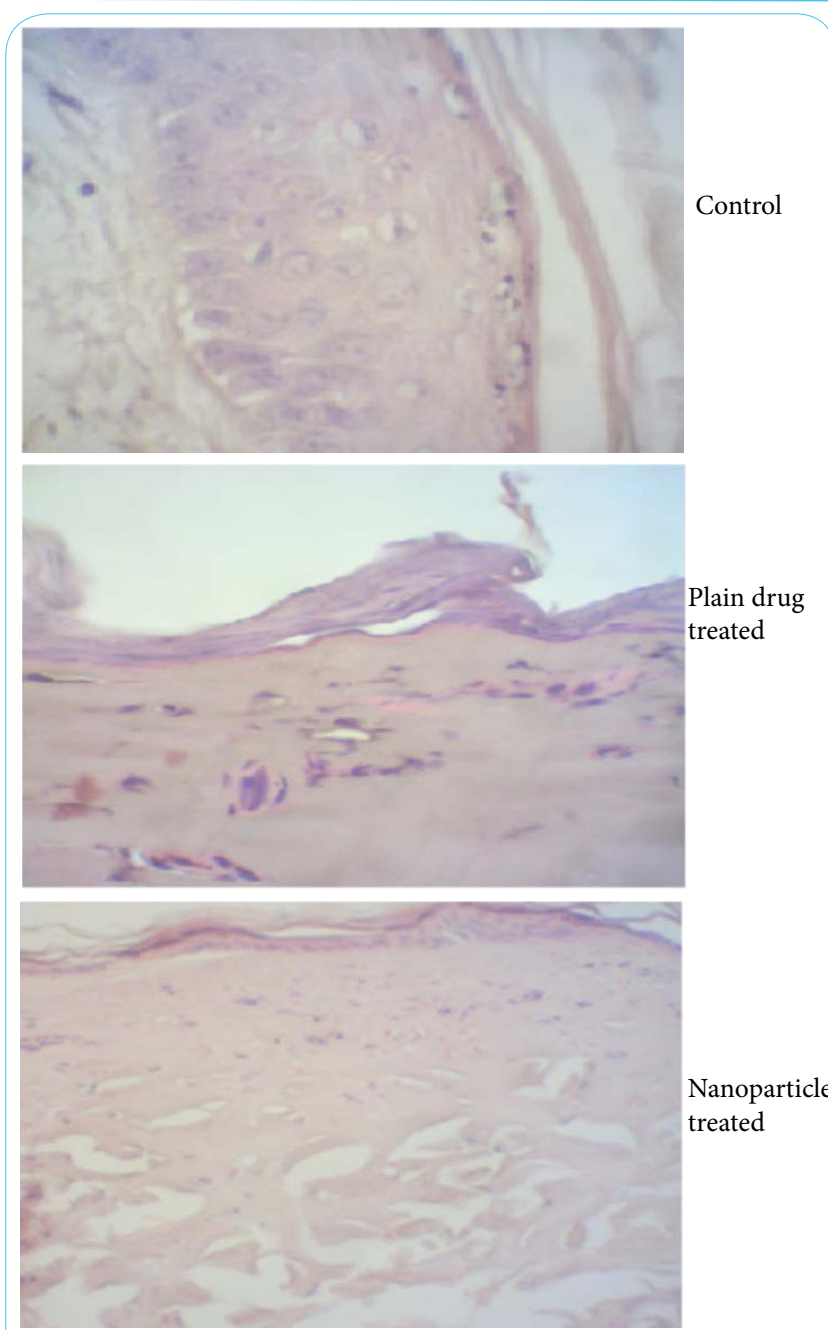

Figure 4: Histopathological evaluation of infected skin area on $7^{\text {th }}$ day post treatment.

combination with $\mathrm{CH}$ and EDTA ( $\mathrm{LF}+\mathrm{CH}+\mathrm{EDTA})$ against both methicillin sensitive and methicillin resistant $\mathrm{S}$. aureus both in vitro and in vivo. Levofloxacin alone showed MIC of $128 \mu \mathrm{g}$ and $256 \mu \mathrm{g}$ against SA and MRSA respectively. The mechanism of action of levofloxacin is inhibition of bacterial topoisomerase IV and DNA gyrase, enzymes required for DNA replication, transcription, repair and recombination. MRSA bacteria are almost found to be resistant to multiple antibiotics. When combined with chitosan in equal concentration, one-fold $\log _{2}$ reduction in MIC against MRSA and two-fold $\log _{2}$ reduction in MIC against MIC was observed. No reduction in $\mathrm{MBC}$ concentration was observed in case of MRSA The exact mechanism for antimicrobial properties of chitosan is still not very clear, however, the interaction of positively charged molecules of chitosan with anionic components of microorganisms, lipopolysaccharides (Gram-negative bacteria) and teichoic acid (Gram-positive bacteria) are considered to be the main reasons [35-40]. Therefore, acidic conditions are required for antimicrobial activity of chitosan since amino groups are ionized only at acidic $\mathrm{pH}$ [41,42]. Also, chitosan's in vitro antimicrobial activity depends on many factors, such as degree of deacetylation, molecular weight of chitosan, its concentration in a solution, or $\mathrm{pH}$ and the ionic strength [43]. However, chitosan's activity is mostly growthinhibitory, where resistant subpopulations might emerge; as a result of physiological adaptation of the cells to chitosan stress [44].
Reports suggest that chitosan antimicrobial activity is markedly increase by addition of EDTA [45-48]. When drug and chitosan solution was combined with EDTA in equal weight ratio, the MIC and $\mathrm{MBC}$ concentrations were three-fold $\log 2$ and two-fold $\log 2$ reduction in MIC against MRSA and MSSA was observed. A study conducted in 2011, evaluated antimicrobial activities chitosan-EDTA combination against Gram-negative and Gram-positive bacteria as well as Candida albicans. EDTA failed to have inhibitory activity against Enterococcus faecalis, a gram positive bacteria, as well as MBC against any of the studied microorganisms. However, chitosanEDTA combination demonstrated synergistic antimicrobial activity against Staphylococcus aureus and an additive effect against other microorganisms [49].

The results of antimicrobial studies were further confirmed by animal studies. $\mathrm{LF}+\mathrm{CH}+\mathrm{EDTA}$ combination showed significant reduction in the diameter of infected area on animal skin from Day 1 of the treatment $(\mathrm{p}<0.05)$ compared to both control and plain drug treated group and complete absence of the infected area was observed after $4^{\text {th }}$ day of treatment.

Thus, it can be concluded that antibiotic with chitosan and EDTA combination is a potential drug delivery system to overcome antibiotic resistance in MRSA and MRSA skin infections. However, further studies with other antibiotic resistant bacterial strains need to be conducted to generalize the applicability of the developed formulation in overcoming antibiotic resistance.

\section{Competing Interests}

The authors declares that they have no competing interests.

\section{References}

1. World Health Organization 2011/2012 (2011) Tuberculosis Global Facts Geneva: World Health Organization.

2. Styers D, Sheehan DJ, Hogan P, Sahm DF (2006) Laboratory-based surveillance of current antimicrobial resistance patterns and trends among Staphylococcus aureus: 2005 status in the United States. Ann Clin Microbiol Antimicrob 5: 2

3. Borg MA, de Kraker M, Scicluna E, et al. (2007) Prevalence of methicillinresistant Staphylococcus aureus (MRSA) in invasive isolates from southern and eastern Mediterranean countries. J Antimicrob Chemother 60: 13101315.

4. Appelbaum PC (2012) 2012 and Beyond: Potential for the Start of a Second Pre-antibiotic Era? J Antimicrob Chemother 67: 2062-2068.

5. Center for Disease Control and Prevention World Health Day: Media Fact Sheet.

6. Center for Disease Control and Prevention (2013) Antibiotic Resistance Threats in the United States.

7. European Medicine Agency The bacterial challenge: time to react. A call to narrow the gap between multidrug-resistant bacteria in the EU and the development of new antibacterial agents.

8. Walsh C (2003) Antibiotics: Actions, Origins, Resistance. American Society for Microbiology (ASM) Press; Washington, DC.

9. Kluytmans J, van Belkum A, Verbrugh H (1997) Nasal Carriage of Staphylococcus aureus: Epidemiology, Underlying Mechanisms, and Associated Risks. Clin Microbiol Rev 10: 505-520.

10. Antibiotic/Antimicrobial Resistance (2013) Center for Disease Control and Prevention (CDC) report.

11. Huang H, Flynn NM, King JH, Monchaud C, Morita M, et al. (2006) Comparisons of Community-Associated Methicillin-Resistant Staphylococcus aureus (MRSA) and Hospital-Associated MSRA Infections in Sacramento, California. J Clin Microbiol 44: 2423-2427. 
Citation: Shahiwala AF, Khan GA, Bostanooei NM (2017) Efficacy of Levofloxacin, Chitosan and EDTA Combination against Methicillin Resistant Staphylococcus Aureus Skin Infections: In Vitro and In Vivo Evaluations. Int J Clin Med Microbiol 2: 121. doi: https://doi.org/10.15344/2456-4028/2017/121

Page 6 of 6

12. Pires NR, Cunha PLR, Maciel JS, Angelim AL, Melo VMM, et al. (2006) Sulfated chitosan as tear substitute with no antimicrobial activity. Carbohydr Polym 91: 92-99.

13. Madhumathi K, Kumar PTS, Abhilash S, Sreeja V, Tamura H, et al. (2010) Development of novel chitin/nanosilver composite scaffolds for wound dressing applications. J Mater Sci Mater Med 21: 807-813.

14. Jayakumar R, Menon D, Manzoor K, Nair SV, Tamura H (2010) Biomedical applications of chitin and chitosan based nanomaterials-A short review. Carbohydr Polym 82: 227-232.

15. Allan CR, Hardwiger LA (1979) The fungicidal effect of chitosan on fungi of varying cell wall composition Experimental Mycology 3: 285-287.

16. Hirano S, Nagao N (1989) Effects of chitosan, pectic acid, lysozyme and chitinase on the growth of several phytopathogens. Agricultural and Biological Chemistry 53: 3065-3066

17. Kendra DF, Hadwiser LA (1984) Characterization of the smallest chitosan oligomer that is maximally antifungal to Fusariumsolani and elicits pisatin formation in Pisumsativum. Exp Mycol 8: 276-281.

18. Uchida Y, Izume M, Ohtakara A, Skjak-Braek G, Anthonsen T, et al. (Eds.), Chitin and chitosan, Elsevier, London, UK, pp. 373

19. Ueno K, Yamaguchi T, Sakairi N, Nishi N, Tokura S, et al. (Eds.), Advances in chitin science, Jacques Andre, Lyon (1997), p. 156.

20. Kittur F, Kumar K andTharanathan RZ (1998) Functional packaging properties of chitosan films Lebensm Unters Forsch 206: 44-47.

21. Brown MRW, Richards RME (1965) Effect of ethylene diaminetetracetate on the resistance of Pseudomonas aeruginosa to antibacterial agents. Nature 207: 1391-1393.

22. Lambert RJ, Hanlon GW, Denyer SP (2004) The synergistic effect of EDTA antimicrobial combinations on Pseudomonas aeruginosa. J Appl Microbio 96: 244-253

23. Sheikh MA, Parker MS (1972) The influence of ethylenediaminetetraacetic acid and phenylethanol upon the fungistatic action of aminacrine hydrochloride. Journal of Pharmacy and Pharmacology 24:118.

24. Hart JR (1984) Chelating agents as preservative potentiators. In: Cosmetic and Drug Preservation: Principles and Practice ed. Kabara, Marcell Dekker JJ, New York, pp. 323-337

25. Vaara M (1992) Agents that increase the permeability of the outer membrane. Microbiological Reviews 56: 395-411.

26. Weiser R, Asscher AW, Wimpenny J (1968) In vitro reversal of antibiotic resistance by ethylenediamine tetraacetic acid. Nature 219: 1365-1366.

27. Larson JE, Morrow SL, Happel L, Sharp JF, Cohen JC (1997) Reversal of cystic fibrosis phenotype in mice by gene therapy in utero. Lancet 349 : 619-620.

28. Sharma M, Visai L, Bragheri F, Cristiani I, Gupta PK, et al. (2008) Toluidine blue- mediated photodynamic effects on staphylococcal biofilms. Antimicrob Agents Chemother 52: 299-305.

29. Raad I, Hanna H, Dvorak T, Chaiban G and Hachem R (2007) Optimal antimicrobial catheter lock solution using different combinations of minocycline, EDTA, and 25 percent ethanol rapidly eradicates organisms embedded in biofilm. Antimicrob Agents Chemother 51: 78-83.

30. Andrews JM (2001) Determination of minimum inhibitory concentrations. J Antimicrob Chemother 48: 5-16.

31. Eliopoulos GM, Eliopoulos CT (1988) Antibiotic combinations: should they be tested? Clin Microbiol Rev 1: 139-156.

32. Eliopoulos GM, Moellering RC (1996) Antimicrobial combinations. In Antibiotics in Laboratory Medicine, 4th ed.; Lorain, V., Ed.; The Williams \& Wilkins Co.: Baltimore, MD, USA, pp. 330-396.

33. Cruishank R, Duguid JP, Marmion BP, Swain RHA (1975) Medical Microbiology. The Practice of Medical Microbiology, 12th ed.; Churchill Livingstone: London, UK

34. Kahkeshani N, Farahanikia B, Mahdaviani P, Abdolghaffari A, Hassanzadeh $\mathrm{G}$, et al. (2013) Antioxidant and burn healing potential of Galiumodoratum extracts. Res Pharma Sci 8: 197-203.

35. Papineau AM, Hoover DG, Knorr D, Farkas DF (1991) Antimicrobial effect of water-soluble chitosans with high hydrostatic pressure. Food Biotechnol 5: 45-57.

36. Sudarshan NR, Hoover DG, Knorr D (1992) Antibacterial action of chitosan Food Biotechnol 6: 257-272.
37. Lim SH, Hudson SM (2004) Synthesis and antimicrobial activity of a watersoluble chitosan derivative with a fiber-reactive group. Carbohydr Res 339 : 313-319.

38. AzizMA, CabralJD, BrooksHJL, MorattiSC, Hanton LR (2012) Antimicrobial properties of a chitosan dextran-based hydrogel for surgical use. Antimicrob Agents Chemother 56: 280-287

39. Lecetal, GuerreroP, Ibarburul, DueñasMT, de la CabaK (2013) Characterization and antimicrobial analysis of chitosan-based films. J Food Eng 116: 889-899.

40. El-Sharif AA and HussainMHM (2011) Chitosan-EDTA new combination is a promising candidate for treatment of bacterial and fungal infections. Curr Microbiol 62: 739-745.

41. Qi LF, Xu ZR, Jiang X, Hu CH, Zou XF (2004) Preparation and antibacteria activity of chitosan nanoparticles. Carbohydr Res 339: 2693-2700.

42. Liu H, Du YM, Wang XH, Sun LP (2004) Chitosan kills bacteria through cell membrane damage. Int J Food Microbiol 95: 147-155.

43. Kong M, Chen XG, Xing K, Park HJ (2010) Antimicrobial properties of chitosan and mode of action: A state of the art review. Int $J$ Food Microbiol 144: 51-63.

44. Raafat D, Von Bargen K, Haas A, Sahl H-G (2008) Insights into the mode of action of chitosan as an antibacterial compound. Appl Environ Microbio 74: $3764-3773$

45. Raafat D, Sahl HG (2009) Chitosan and its antimicrobial potential-a critical literature survey. Microbial Biotechnology 2: 186-201.

46. Tsai GJ, Su WH (1999) Antibacterial activity of shrimp chitosan against Escherichia coli. J Food Prot 62: 239-243.

47. Jumaa M, Furkert FH, Muller BW (2002) A new lipid emulsion formulation with high antimicrobial efficacy using chitosan. Eur J Pharm Biopharm 53: 115-123.

48. No HK, Park NY, Lee SH, Meyers SP (2002) Antibacterial activity of chitosans and chitosan oligomers with different molecular weights. Int $J$ Food Microbiol 74: 65-72.

49. El-Sharif AA, Hussain MH (2011) Chitosan-EDTA new combination is a promising candidate for treatment of bacterial and fungal infections. Curr Microbiol 62: 739-745. 